\title{
The EFFectiveness of MANual HyPerinflation DURING THE PHYSIOTHERAPY MANAGEMENT OF ACUTE ATElectasis: A CASE REPORT
}

\begin{abstract}
Atelectasis is common in intubated and ventilated patients. The reasons for the atelectasis are multifactorial. Atelectasis, if prolonged, may lead to hypoxaemia, pulmonary infection and fibrosis. The effectiveness of manual hyperinflation as an adjunct to standard respiratory physiotherapy management of patients in the ICU to re-inflate collapsed lung regions, to improve gas exchange and respiratory compliance and to assist with the removal of secretions, have been proclaimed by numerous authors. This case report demonstrates the effectiveness of the addition of manual hyperinflation to the physiotherapy management of an intubated patient with acute atelectasis.
\end{abstract}

\section{VAN ASWEGEN H, MSc Physiotherapy'; EALES C], PhD'}

1 Lecturer, Physiotherapy Department, University of the Witwatersrand.

2 Head School of Therapeutic Sciences, University of the Witwatersrand.

KEY WORDS: ACUTE ATELECTASIS, ASPIRATION, MANUAL HYPERINFLATION, MODIFIED POSTURAL DRAINAGE.

\section{INTRODUCTION}

Pulmonary complications such as atelectasis, secretion retention and nosocomial pneumonia are common in intubated and mechanically ventilated patients (Ntoumenopoulos et al, 1998). Mechanical ventilation leads to reduced functional residual capacity, increased ventilation: perfusion mismatching, decreased compliance and a reduction in surfactant (Scanlan et al, 1995; Jones, 1997).

Several research articles have been published evaluating the role of physiotherapy in the intensive care unit (ICU). The aims of physiotherapy management of patients in the ICU are to prevent complications by improving mucociliary clearance and alveolar expansion, to maintain or improve cardiopulmonary function and to maximize musculoskeletal performance and oxygenation (Ciesla, 1996; Jones, 1997; Denehy 1999).

The effectiveness of manual hyperinflation as an adjunct to standard respiratory physiotherapy management of patients in the ICU to re-inflate collapsed lung regions, to improve gas exchange and respiratory compliance and to assist with the removal of secretions, have been proclaimed by numerous authors (Stiller et al, 1990; Rothen et al, 1993; Barker et al, 1994; Maxwell et al, 1998; McCarren et al, 1998; Hodgson et al, 2000; Berney et al, 2002). However, despite this evidence, many physiotherapists in South Africa are reluctant to use manual hyperinflation in the management of their intensive care patients.

\section{LITERATURE REVIEW}

Manual hyperinflation is a technique which provides a greater than baseline tidal volume to the lungs. It was first described in 1968 as "bag squeezing" and the technique involved inflating the lungs with oxygen and delivering tidal volumes of $1.0 \mathrm{~L}$, requiring a peak inspiratory pressure of between 20 and $40 \mathrm{cmH}_{2} \mathrm{O}$. More recent definitions include: the delivery of tidal volumes to achieve airway pressures of up to 40 $\mathrm{cmH}_{2} \mathrm{O}$ to successfully recruit atelectatic lung segments (Rothen et al, 1993; Denehy, 1999) or a tidal volume that is $50 \%$ greater than that delivered by the ventilator (Singer et al, 1994). Peak inspiratory pressures between 40 and $50 \mathrm{cmH}_{2} \mathrm{O}$ have been associated with alveolar rupture (Denehy, 1999). This is followed by an inspiratory pause of 2 seconds and a quick release of pressure on expiration, leading to a rapid flow of air, simulating the effect of a cough (Hodgson et al, 2000; Berney et al, 2002). The manual hyperinflation circuits most commonly used by physiotherapists internationally are the Magill, Mapleson C, Laerdal and AirViva circuits. These types of circuits have been shown to influence the delivered tidal volumes and pressures (Denehy, 1999). The Laerdal circuit is the resuscitation circuit used most frequently in South African hospitals.

Atelectasis is common in intubated and ventilated patients. The reasons for the atelectasis are multifactorial and include low volume ventilation strategies. Atelectasis, if prolonged, may lead to hypoxaemia, pulmonary infection and fibrosis. In addition, loss of lung volume and atelectasis lead to a progressive reduction in pulmonary compliance making ventilation more difficult (Berney et al, 2002). It is proposed that the reduction in functional residual capacity is caused by the loss of respiratory muscle tone during mechanical ventilation and by the compression of the dependent parts of the lungs rather than by the absorption of gas behind the closed airways (Rothen et al, 1993).

In a study done by Stiller in 1990, the researchers attempted to determine if multimodality physiotherapy treatment

\section{CORRESPONDENCE TO:}

Heleen van Aswegen

Physiotherapy Department

University of the Witwatersrand

Tel: (011) 7173702

Fax: (011) 7173719

e-mail: vanaswegenh@therapy.wits.ac.za 
was more effective than a simple physiotherapy treatment in resolving acute lobar atelectasis. Patients in group 1 received treatment incorporating positioning, vibrations, manual hyperinflation and suctioning. Patients in group 2 were treated with manual hyperinflation and suctioning alone. Although this study was restricted in patient numbers, the authors found that during the initial stages of acute lobar atelectasis, a basic physiotherapy treatment of manual hyperinflation and suctioning was enhanced by the addition of positioning and vibrations (Stiller et al, 1990). In a follow-up study done by Stiller in 1996 the researchers compared five physiotherapy regimens in the treatment of acute lobar atelectasis. The results suggested that modified postural drainage was an effective additional component to manual hyperinflation and suction performed hourly for 6 hours (Stiller et al, 1996). Because of the potential complications of persistent atelectasis, an aggressive approach to its treatment is advocated.

\section{CASE HISTORY}

A 34-year old male was admitted to the casualty department of a government hospital in the Johannesburg region, on $10 / 08 / 2003$, after being assaulted. He sustained severe facial lacerations with resultant facial oedema and presented with a very low Glascow Coma Scale (GCS) rating (medical records did not state the exact score). A computedtomography examination revealed no cerebral oedema or facial fractures and the aortic arch angiogram was normal. The patient was admitted to one of the hospital wards for observation and standard nursing care. No referral was made to physiotherapy at this time. Four days after admission the patient's GCS was still low and he suddenly developed severe respiratory distress. The patient was intubated and admitted to the Intensive Care Unit (ICU).

\section{PHYSICAL EXAMINATION}

Following intubation, examination of the chest x-ray revealed a total collapse of the right lung with the endotracheal tube situated at level T2 (see Figure 1). See Table 1 for arterial blood gas results at 08:00 hours on Thursday, 14/08/2003. This indicated a severe hypoxaemia with respiratory acidosis. The ventilation mode was set at pressure control with a peak airway pressure of $33 \mathrm{cmH}_{2} \mathrm{O}$, positive end-expiratory pressure (PEEP) of $10 \mathrm{cmH}_{2} \mathrm{O}$, pressure support of $20 \mathrm{cmH}_{2} \mathrm{O}$ and a ventilation rate of $20 \mathrm{breaths} / \mathrm{min}$. The patient was lying in supine with his head elevated to $30^{\circ}$ to reduce the facial oedema. The patient was sedated with morphine and dormicum. Chest wall asymmetry was present with no expansion on the right side. Auscultation to the right lung revealed no breath sounds in the anterior, lateral or posterior lung segments.

\section{INTERVENTION}

The first physiotherapy treatment session started at 08:30. The patient was positioned in left side lying, maintaining the head elevation at $30^{\circ}$. Chest percussions and vibrations were applied to the posterior and lateral segments of the right lung for 5 - 7 minutes. Thereafter manual hyperinflation was performed through a Laerdal resuscitation circuit for 5 minutes whilst the nursing sister prepared for suctioning. An oxygen flow rate of $15 \mathrm{~L} / \mathrm{min}$ and a PEEP valve = $10 \mathrm{cmH}_{2} \mathrm{O}$ were used for the manual hyperinflation treatment. The PEEP valve was used to prevent further hypoxaemia whilst the patient was disconnected from the ventilator. The manual hyperinflation technique consisted of an inspiratory phase that was followed by a 2-second inspiratory pause followed by expiration which was unobstructed. The patient was suctioned in the left side lying position, whilst a second physio-

\section{Figure 1}

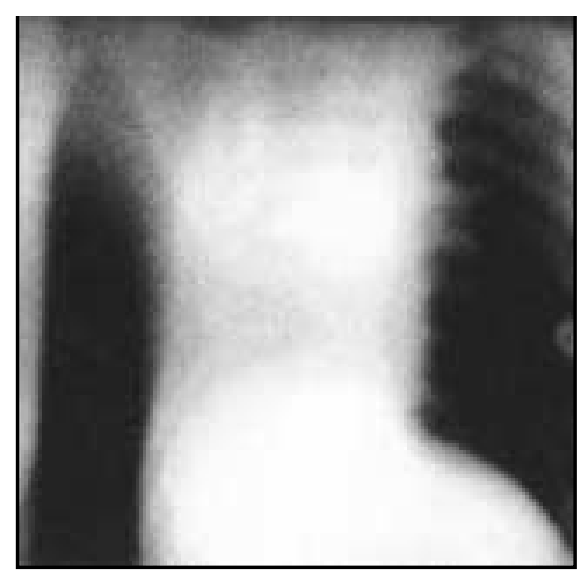

therapist applied chest wall shaking to the posterior and lateral lung segments during expiration to facilitate optimal secretion clearance. Twenty milliliters of saline was installed, at 5 millilitres per installation, into the endotracheal tube during the suctioning procedure, to enhance secretion removal. Manual hyperinflation was administered intermittently during this suctioning procedure, which lasted approximately 5 minutes. Copious amounts of yellow-orange coloured secretions were removed on suctioning. The treatment session lasted for 20 minutes and no changes in cardiovascular status were noted throughout the treatment. Following the treatment, the patient was reconnected to the ventilator and left in left side lying for another 30 minutes to promote ventilation of the right lung. This same treatment regimen was repeated at 11:00 and $14: 30$ on the same day.

\section{OUTCOME}

The assessment after the first treatment revealed that chest wall expansion of the upper and mid-lung regions of the right lung had improved significantly but reduced expansion was still present in the lower regions of the right lung. Auscultation revealed improved breath sounds in the apical, anterior and posterior segments of the right upper lobes and the right middle lobe and was reduced in the lower lobes.

The arterial blood gas results taken at 10:00, 12:00 and 16:00 on 14/08/2003 and for 08:00 and 10:00 on 15/08/2003 indicated a marked improvement between the first two treatments and then plateaued (see Table 1). The ventilator

\section{Figure 2}

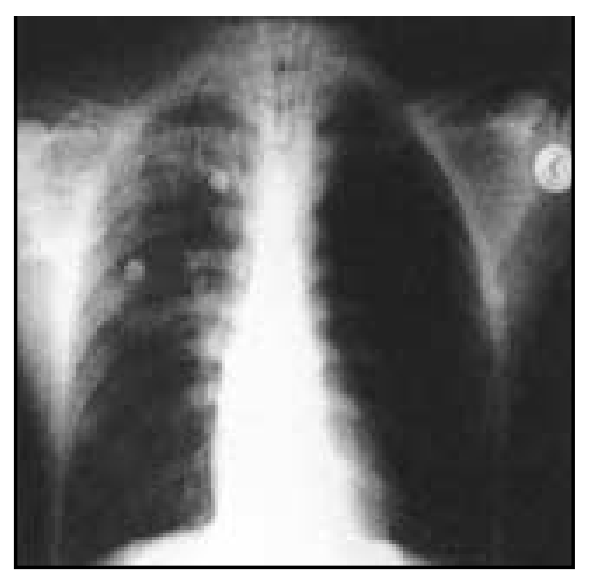


Table 1: Arterial Blood Gas Results

\begin{tabular}{|c|c|c|c|c|c|c|}
\hline & \multicolumn{4}{|c|}{$14 / 08 / 2003$} & \multicolumn{2}{|c|}{$15 / 08 / 2003$} \\
\hline & $08: 00$ & $10: 00$ & $12: 00$ & $16: 00$ & 08:00 & $10: 00$ \\
\hline pH & 7.2 & 7.38 & 7.37 & 7.47 & 7.46 & 7.47 \\
\hline $\begin{array}{l}\mathrm{PaCO}_{2} \\
\text { (mmHg) }\end{array}$ & 70.2 & 42.7 & 44.9 & 33.9 & 40.5 & 36.1 \\
\hline $\begin{array}{l}\mathrm{PaO}_{2} \\
\text { (mmHg) }\end{array}$ & 44.1 & 264 & 129 & 152 & 134 & 146 \\
\hline $\begin{array}{l}\mathrm{HCO}_{3} \\
((\mathrm{~mol} / \mathrm{L})\end{array}$ & 27.4 & 24.8 & 25.3 & 24.6 & 29 & 26.4 \\
\hline BE & 2.5 & 0.1 & 0.3 & 1.7 & 5 & 3.2 \\
\hline $\mathrm{SaO}_{2}(\%)$ & 78.7 & 100 & 99.5 & 100 & 100 & 100 \\
\hline $\mathrm{FiO}_{2}$ & 1 & 1 & 0.6 & 0.5 & 0.4 & 0.4 \\
\hline
\end{tabular}

$\mathrm{PaCO}_{2}=$ partial pressure of carbon dioxide in arterial blood; $\mathrm{PaCO}_{2}=$ partial pressure of oxygen in arterial blood; $\mathrm{HCO}_{3}=$ standard bicarbonate; $\mathrm{BE}=$ base excess; $\mathrm{SaO}_{2}=$ oxygen saturation in arterial blood; $\mathrm{FiO}_{2}=$ fraction of inspired oxygen

Table 2: Ventilation Parameters

\begin{tabular}{|l|c|c|c|c|c|c|}
\hline & \multicolumn{4}{|c|}{$\mathbf{1 4 / 0 8 / 2 0 0 3}$} & \multicolumn{2}{c|}{ 15/ 08/ 2003 } \\
\hline & $\mathbf{0 8 : 0 0}$ & $\mathbf{1 0 : 0 0}$ & $\mathbf{1 2 : 0 0}$ & $\mathbf{1 6 : 0 0}$ & $\mathbf{0 8 : 0 0}$ & $\mathbf{1 0 : 0 0}$ \\
\hline Mode & PC & PC & PC & PC & PSV & PSV \\
\hline PEEP & 10 & 10 & 10 & 10 & 10 & 10 \\
\hline PIP & 36 & 24 & 24 & 25 & 21 & 20 \\
\hline PS & 20 & 20 & 20 & 20 & 12 & 10 \\
\hline $\begin{array}{l}\text { Rate } \\
\text { (Set/ Pt) }\end{array}$ & $20 / 0$ & $20 / 0$ & $20 / 0$ & $20 / 0$ & $10 / 14$ & $10 / 14$ \\
\hline
\end{tabular}

$\mathrm{PC}=$ pressure control ventilation; PSV = pressure support ventilation; PEEP = positive endexpiratory pressure; PIP = peak inspiratory pressure; PS = pressure support

parameters are displayed in Table 2. The chest x-ray taken at 09:00 on Friday, 15/08/2003 (see Figure 2), showed the right lung fully re-inflated with an area of consolidation in the right upper lobes.

On physiotherapy assessment of the chest the next day (15/08/2003), the chest wall symmetry was restored and auscultation revealed normal breath sounds throughout the right lung with no added sounds found.

\section{DISCUSSION}

The use of manual chest therapy techniques in a modified postural drainage position together with manual hyperinflation, saline installation and suctioning proved to be beneficial to this patient with regards to re-inflation of the collapsed lung and improved oxygenation and ventilation. The cause of the atelectasis is speculated to be aspiration. This conclusion was made from the gastric- like contents that were removed from the lungs during physiotherapy treatment. This possible aspiration probably led to the patient's sudden deterioration on the ward. The patient's depressed level of consciousness on the ward most likely inhibited his ability to protect his airway. Saliva and other oral contents could have leaked into the lungs due to depressed swallowing reflex. The patient was fed through a nasogastric tube on the ward but it is not clear whether he received gastric suctioning. The absence of gastric suctioning could have led to raised intra-abdominal pressure due to collection of fluid in the stomach, causing gastro-oesophageal reflux and the possibility of aspiration into the right main bronchus whilst being nursed in side-lying, can thus not be excluded (Hough, 2001). The ventilation data indicates that the patient was being weaned from mandatory ventilation to intermittent mandatory ventilation by $15 / 08 / 2003$ due to the great improvement in oxygenation and ventilation. The patient received a tracheostomy two days later to assist in the weaning process. Five days later the patient was weaned onto a T-piece and was transferred to the high-care unit. At the time of writing this report (three weeks later), the patient had not regained a normal level of consciousness and his attending physician was raising the possibility of axonal hypoxia as a possible cause for his low Glasgow Coma Scale rating. The reduction in the amount of time spent on mechanical ventilation was beneficial to the patient with regards to reduced risk of contracting nosocomial infections. A reduction in the amount of days spent on mechanical ventilation also helps to reduce costs for the intensive care unit and the hospital.

\section{SUMMARY}

The drastic improvement in oxygenation after the first treatment and the resolution of the atelectasis of the right lung within 24 hours, indicates the effectiveness of early physiotherapy treatment for patients with atelectasis and/or aspiration in the intensive care unit. The addition of manual hyperinflation as an adjunct to physiotherapy treatment was proved to be safe and effective. A limitation of this case report is that a manometer was not used in the manual hyperinflation circuit to monitor the amount of airway pressure generated through the lungs during the physiotherapy treatment sessions. The use of a manometer is not standard practice in this specific hospital's ICU. In 1999, Hodgson did a survey of manual hyperinflation in Australian hospitals and found that only $31 \%$ of physiotherapists used a manometer in the resuscitation circuits to monitor airway pressure during manual hyperinflation.

The findings of this case report confirm results from previous studies regarding the effectiveness of manual hyperinflation as an adjunct to physiotherapy treatment and the effectiveness of physiotherapy management of patients that suffer from acute atelectasis and/or aspiration. Barker stated in 1994 that "manual hyperinflation should not be 
regarded as an 'all or nothing' technique which is routinely applicable but rather as a modality with its own set of indications, contra-indications and precautions for its use."

\section{REFERENCES}

Ntoumenopoulos G, Gild A, Cooper DJ 1998 The effect of manual lung hyperinflation and postural drainage on pulmonary complications in mechanically ventilated trauma patients. Anaesth Intensive Care 26: 492 - 496

Jones A 1997 Physiotherapy in Intensive Care. In: Oh T, ed. Intensive Care Manual. Pp 26 -31. 4th ed. Oxford, Butterworth Heinemann

Scanlan CL, Blazer C 1995 Physics and Physiology of Ventilatory Support In: Spearman C, Sheldon R, Egan D, eds. Egan's Fundamentals of Respiratory Therapy. Pp 825 - 863. 6th ed. St Louis, CV Mosby

Ciesla N 1996 Chest physical therapy for patients in the intensive care unit. Phys Ther 76: $609-625$
Denehy L 1999 The use of manual hyperinflation in airway clearance. Eur Respir J 14: $958-965$

Stiller K, Geake T, Taylor J, Grant R, Hall B 1990 Acute lobar atelectasis: a comparison of two chest physiotherapy regimens. Chest 98 : $1336-1340$

Stiller K, Jenkins S, Grant R, Geake T, Taylor J, Hall B 1996 Acute lobar atelectasis: a comparison of five physiotherapy regimens. Physiotherapy Theory and Practice 12(4): 197 - 209

Rothen HU, Sporre B, Engberg G, Wegenius G, Hedenstierna G 1993 Re-expansion of atelectasis during general anaesthesia: a computed tomography study. Br J Anaesth 71: $788-795$

Barker M, Eales CJ 1994 Ambubagging as a therapeutic technique: clinical guidelines. Physiotherapy 50(2): $26-27$

Maxwell L, Ellis E 1998 Secretion clearance by manual hyperinflation: possible mechanisms. Physiotherapy Theory and Practice 14: $189-197$

McCarren B, Chow CM 1998 Description of manual hyperinflation in intubated patients with atelectasis. Physiotherapy Theory and Practice 14: 199 - 210

Hodgson C, Denehy L, Ntoumenopoulos G, Santamaria J, Carroll s 2000 An investigation of the early effects of manual lung hyperinflation in critically ill patients. Anaesth Intensive Care 28: 255 - 261

Berney S, Denehy L 2002 A comparison of the effects of manual and ventilator hyperinflation on static lung compliance and sputum production in intubated and ventilated intensive care patients. Physiotherapy Research International 7(2): $100-108$

Singer M, Vermaat J, Hall G, Latter G, Patel M 1994 Hemodynamic effects of manual hyperinflation on critically ill mechanically ventilated patients. Chest 106(4): 1182 - 1187

Hodgson C, Carroll S, Denehy L 1999 A survey of manual hyperinflation in Australian hospitals. Australian Journal of Physiotherapy 45(3): 185 - 193

Hough A 2001 Pulmonary manifestations of systemic disease. In: Physiotherapy in Respiratory Care: An evidence-based approach to respiratory and cardiac management. Pp 115. 3rd edition. Nelson Thornes, Cheltenham
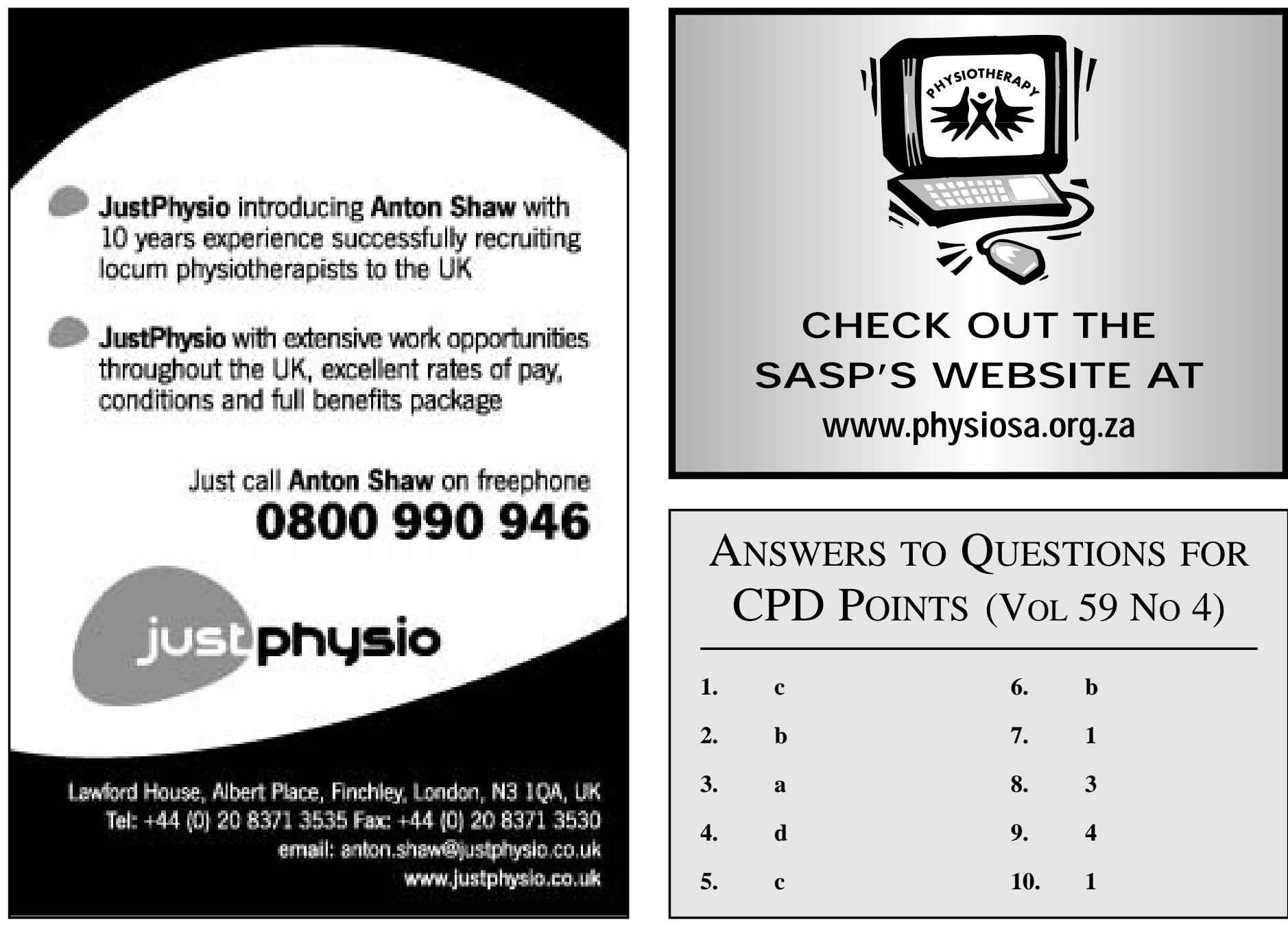

\section{ANSWERS TO QUESTIONS FOR CPD PoInTs (Vol 59 No 4)}

$\begin{array}{lrll}\text { 1. } & \text { c } & 6 . & \text { b } \\ \text { 2. } & \text { b } & 7 . & 1 \\ \text { 3. } & \text { a } & 8 . & 3 \\ \text { 4. } & \text { d } & 9 . & 4 \\ \text { 5. } & \text { c } & 10 . & 1\end{array}$

